\title{
Postoperative Vocal Cord Dysfunction Despite Normal Intraoperative Neuromonitoring: An Unexpected Complication With the Risk of Bilateral Palsy
}

\author{
George H. Sakorafas
}

Published online: 2 December 2014

(C) Société Internationale de Chirurgie 2014

\section{Dear Editor,}

I read with interest the paper by Melin M et al., recently published in the World Journal of Surgery [1]. It is interesting to note the occurrence of delayed vocal cord palsy in four patients of this study. It would be of interest to know what is the opinion of the authors about the possible etiopathogenesis for this complication. Obviously, an injury of the recurrent laryngeal nerve will result in VCP immediately after surgery (use of diathermy?, use of hemostatic material in contact with the nerve causing granulomatous changes after some time?). I would also like to remind that the routine use of intraoperative neuromonitoring remains controversial; at this time of crisis, the cost is a parameter that should be taken seriously into consideration. I enjoyed reading the paper.

\section{Reference}

1. Melin M, Schwarz K, Pearson MD et al (2014) Postoperative vocal cord dysfunction despite normal intraoperative neuromonitoring: an unexpected complication with the risk of bilateral palsy. World J Surg 38(10):2597-2602. doi:10.1007/s00268-014-2591-2
G. H. Sakorafas $(\bowtie)$

Department of Surgical Oncology, Saint Savvas Cancer

Hospital, Athens, Greece

e-mail: georgesakorafas@yahoo.com 